NEWS

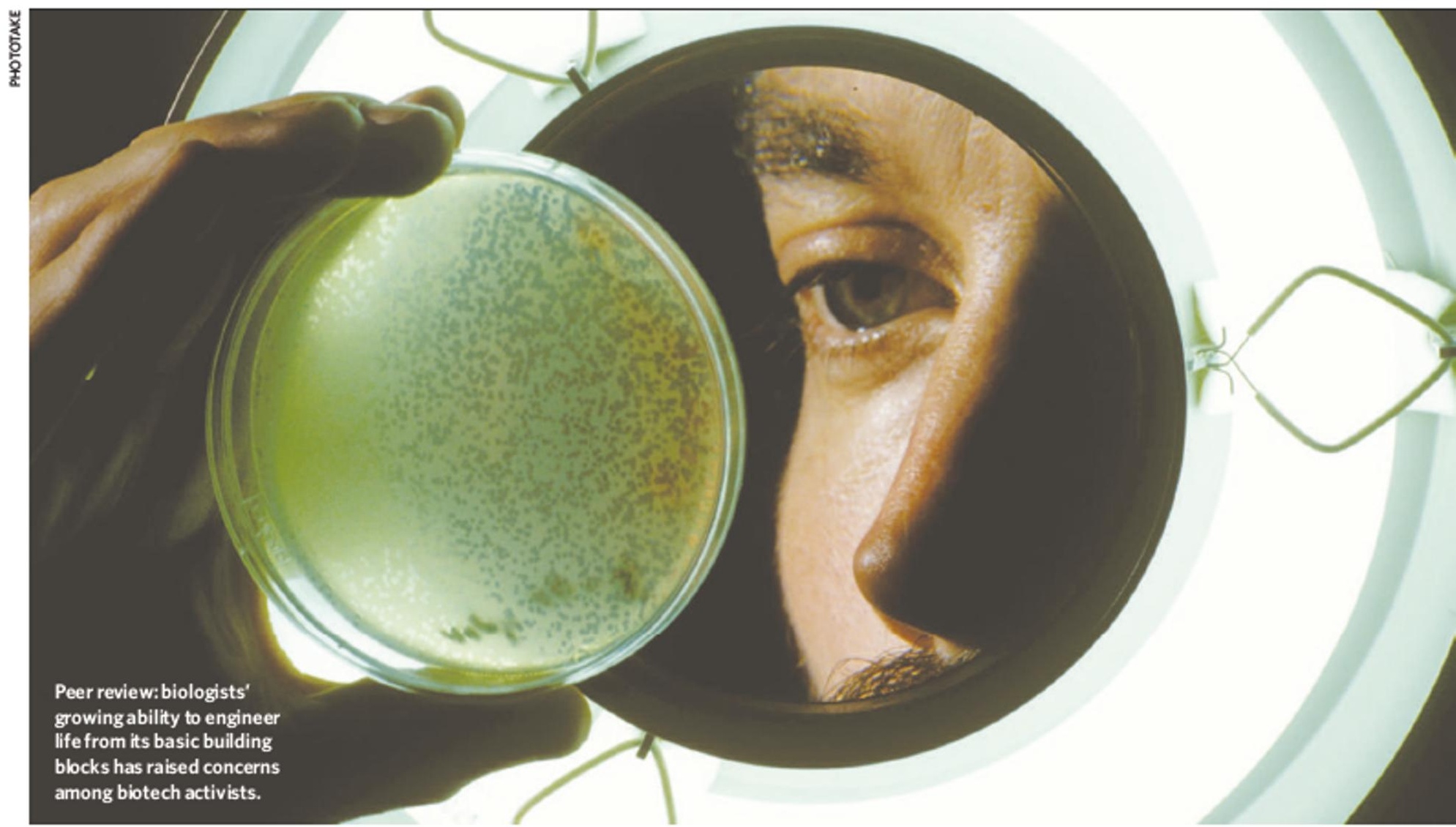

\title{
Synthetic biologists try to calm fears
}

\section{BERKELEY, CALIFORNIA}

Researchers in the field of synthetic biology are to issue a declaration of intent about professional behaviour and organization in order to ensure good practice and to address a range of concerns about their research. The scientists hope to ensure that controversy doesn't choke the field just as it begins to make progress. But critics are likely to be unimpressed - a coalition of organizations concerned about the technology released an open letter ahead of the meeting calling for the field to be externally regulated.

The scientists and engineers meeting this week in Berkeley for the Synthetic Biology 2.0 conference discussed recent advances towards their goal of being able to develop biological systems from scratch. But they also devoted a day of the meeting to issues of intellectual property, biosecurity, risks and standards. As Nature went to press, participants were drafting a set of statements to be posted online (http://pbd.lbl.gov/sbconf) for others to comment on. They intend to present this as an outcome of the meeting.

One suggestion discussed at the conference was a possible commitment to buy synthesized DNA only from companies that screen orders for safety and security concerns, for instance by checking them against a list of dangerous pathogens. The community hopes this would force companies that do not already use such methods to adopt them, making it harder for those with malicious intentions to obtain deadly DNA.

The synthetic biologists hope that, by regulating themselves, they can stave off attempts to set controls or limits on the field. The science is moving rapidly: at the meeting, for example, Chris Voigt from the University of California, San Francisco, reported that his lab has engineered Salmonella bacteria to make and secrete protein components - a difficult task made easier by thelab's deliberate simplification of the genetic code for the proteins. And Jeff Boeke from the Johns Hopkins University in Baltimore, Maryland, has built, from scratch, a retrotransposon - a genetic element capable of jumping around the genome. Boeke's retrotransposon is designed to be a far more effective 'jumper' than natural retrotransposons, and indeed, inserts itselfinto many more places in the genome.

\section{Laboratory life}

Such early success has synthetic biologists dreaming of far grander projects. Boeke, for instance, is gathering support for the idea of engineering synthetic yeast organisms, making them compete against each other, and watching which strains evolve. George Church's lab at the Massachusetts Institute of Technology (MIT) in Boston, is making synthetic stretches of Escherichia coli DNA with the goal of 'optimizing' the bacterium's genome and reconstituting it from scratch. Drew Endy at MIT has already done this with a T7 bacteriophage. And while other scientists have built whole viruses from synthetic DNA by simply ordering viral DNA from a genesynthesis company (see Nature 418, 265; 2002), synthetic biologists envisage something different. Their goal is to strip genomes down to their essential parts to try to learn more 
about the principles behind the architecture of life.

"The time is right for this," Boeke says. "This would allow us to answer functional questions we can't ask in any other way."

But as exciting as these ideas are, they also raise concerns about the proper use of such technology. A coalition of organizations traditionally concerned about biotechnology, including the ETC Group, Greenpeace and GeneWatch UK, submitted an open letter to the synthetic biologists and to media before the meeting, protesting against the biologists' self-regulating approach. ${ }^{\alpha}$ We believe that this potentially powerful technology is being developed without proper societal debate concerning socioeconomic, security, health, environmental and human rights implications," the letter states.

\section{Enemy agents?}

Companies have already run up against biosecurity issues. Jeremy Minshull, president and co-founder of the company DNA 2.0, and Hans Bügl of Geneart, based in Regensburg, Germany, have both turned away orders for potentially hazardous DNA. In Geneart's case, an Indian customer ordered a stretch of DNA that is banned for export by the German government. In Minshull's case, a client ordered a pathogen on the 'select agent' list of organisms issued by the US Centers for Disease Control and Prevention (CDC). No one at the agency could tell Minshull how to handle this sensitive order, so he cancelled it. In both cases, the companies believed the customers had good intentions. The DNA 2.0 case is particularly worrying, says Gerald Epstein of the Center for Strategic and International Studies in Washington DC: ${ }^{\alpha} \mathrm{CDC}$ implements a select agent list, but it doesn't say anything about what happens if somebody suspects somebody else of doing something bad."

Ultimately, the synthetic biologists said at the meeting, the best way to deal with these issues is to pursue projects that benefit society. For instance, Jonathan Eisen of the University of California, Davis, said the community can make a positive contribution to biodefence by engineering ways to tag and track DNA. This might help pinpoint the source of biological attacks. Such efforts could win public support for the technology, and this will be crucial for the field's future, said David Baltimore, president of the California Institute of Technology in Pasadena: "We have to remind everyone that we are working towards a greater good."

Erika Check

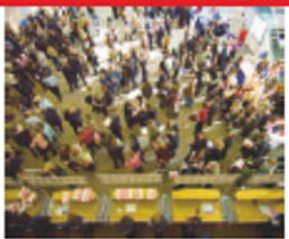

CONFERENCEREPORTS

Morenews and diary entries from this weeks

Synthet ic Biology 2.0 meeting.

www.nat ure.com/news

\section{Mars explorers seek spot for touchdown}

More than 125 planetary scientists will gather in Pasadena, California, next week to begin planning NASA's next steps on Mars - or rather, where that step should fall. The workshop will rank more than 40 candidate landing sites for the Mars Science Laboratory (MSL), a rover slated to depart for the planet in September 2009. There will be no hasty decisions: NASA plans three more workshops after this one, and will choose the final site a month before launch.

NASA says the MSL will improve in every way on the Spirit and Opportunity rovers now exploring Mars. Its ten instruments weigh a total of $75 \mathrm{~kg}$, compared with five instruments weighing $9 \mathrm{~kg}$ on the current rovers. It will be able to land within a 20 km-diameter target circle, anywhere within $60^{\circ}$ north or south of the martian equator, instead of being restricted to a narrow band around the planet's middle. And it will be able to negotiate rougher and steeper terrain than Spirit and Opportunity and travel further - at least 20 kilometres.

With so many options for where to land, workshop co-chairman John Grant of the Smithsonian National Air and Space Museum's Center for Earth and Planetary Studies feared scientists would suggest thousands of candidate sites. "We were quite relieved to find out that the number of sites is manageable," he says. The first workshop's goal is to rank the sites as high, medium or low priority for detailed study using cameras and other instruments orbiting Mars.

The MSL will continue the work of its predecessors in tracing the history of water on Mars. Geologists would prefer to explore an area where many layers of rock are exposed, to give a large cross-section through time. The less dust covering the rocks, the better. The site must also be navigable for a wheeled rover, without too manyobstades. And particularly prized will be areas where scientists believe water once settled in quiet pools that may have provided habitats for ancient martian life (see 'Candidatelanding sites').

Another improvement on past rover missions is that scientists will know more about the landing sites in advance. Since Spirit and Opportunity arrived on Mars in January 2004, Mars Express and the Mars Reconnaissance Orbiter (MRO) have begun their own study of the surface. The MRO's High Resolution Imaging Science Experiment may be able to spot outcrops from orbit of the kind that Spirit and Opportunity have visited.

Tony Reich hardt

\section{CANDIDATE LANDING SITES}

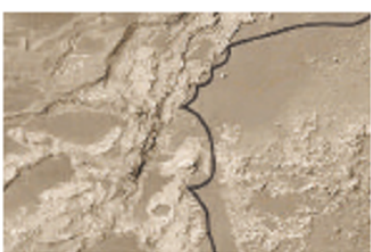

\section{SEDIMENTARY FANS}

A rover in the Eberswalde crater could roam (black line) among fan-shaped sedimentary deposits at the end of flow channels, pausing at rock exposures. Eberswalde's features suggest that there was once standing water there. Plus, the crater floor is flat, making for easy travel.

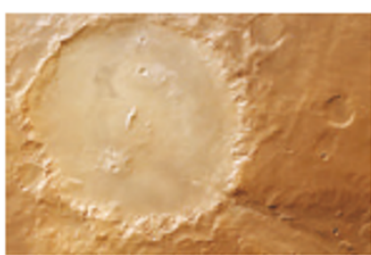

CRATER FLOORS

At least 50 metres of water is believed to have pooled in some parts of Holden crater, one of a string of large, ancient craters in Mars's southern hemisphere. Fan-shaped sediments near the crater's centre suggestcalm waters where life might once have taken hold.

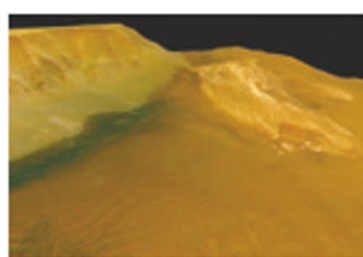

SULPHATE DEPOSITS

The OMEGA spectrometer on the European Mars Express has found minerals such as sulphate and phyllosilicates that form in water, making them candidates for further exploration. The sulphate deposits pictured here are in a canyon called the Juventae Chasma. 